\title{
Neural correlates of feeling sympathy
}

\author{
Jean Decety ${ }^{\mathrm{a}, \mathrm{b}, *}$, Thierry Chaminade $\mathrm{a}^{\mathrm{a}, \mathrm{b}}$ \\ ${ }^{a}$ University of Washington Center for Mind, Brain and Learning, P.O. Box 357988, Seattle, WA 98195, USA \\ ${ }^{\mathrm{b}}$ Inserm Unit 280, 151 Cours Albert Thomas, 69424 Lyon Cedex 3, France
}

\begin{abstract}
Positron emission tomography (PET) was used to investigate the neural correlates of feeling sympathy for someone else (i.e. the affinity, association, or relationship between persons wherein whatever affects one similarly affects the other). While undergoing PET scans, subjects were presented with a series of video-clips showing individuals (who were semi-professional stage actors) telling sad and neutral stories, as if they had personally experienced them. These stories were told with either congruent or incongruent motor expression of emotion (MEE). At the end of each movie, subjects were asked to rate the mood of the communicator and also how likable they found that person. Watching sad stories versus neutral stories was associated with increased activity in emotion processing-related structures, as well as in a set of cortical areas that belong to a "shared representation" network, including the right inferior parietal cortex. Motor expression of emotion, regardless of the narrative content of the stories, resulted in a specific regional cerebral blood flow (rCBF) increase in the left inferior frontal gyrus. The condition of mismatch between the narrative content of the stories and the motor expression of emotion elicited a significant skin conductance response and strong $\mathrm{rCBF}$ increase in the ventromedial prefrontal cortex and superior frontal gyrus which are involved in dealing with social conflict. Taken together, these results are consistent with a model of feeling sympathy that relies on both the shared representation and the affective networks. Interestingly, this network was not activated when subjects watched inappropriate social behavior.
\end{abstract}

(C) 2002 Elsevier Science Ltd. All rights reserved.

Keywords: Sympathy; Empathy; Intersubjectivity; Shared representations; Neuroimaging

\section{Introduction}

Many philosophers and psychologists have proposed that prosocial behavior is often motivated by sympathy or empathy. For instance, in his Treatise of Human $\mathrm{Na}$ ture (1739/1888), Hume [52], observed that our minds are mirror to one another: they reflect one another's passions, sentiments, and opinions. This "sympathy" or "propensity we have to sympathize with others, to receive by communication [the] inclinations and sentiments [of others], however different from, or even contrary to, our own," he held to be the chief source of moral distinctions. For his colleague Smith [79], sympathy is our ability to feel with other persons and it is a universal feature of human nature.

This conception of sympathy, dating from the time of the Enlightenment, is well supported today by a mass of converging evidence from developmental psychology and cognitive neuroscience. It should be noted, however, that there are many definitions of sympathy and empathy, al-

\footnotetext{
* Corresponding author. Tel.: +1-206-543-7357; fax: +1-206-543-8423.

E-mail address: decety@u.washington.edu (J. Decety).
}

most as many as there are researchers who study the topic (e.g. $[9,20-59,80]) .{ }^{1}$ Notably, Wispé [86] described empathy as an effortful process by which we try to comprehend another's experience, while sympathy would be a direct perceptual awareness of another person's experience akin to the phenomenon of sympathetic resonance. Yet most scholars would agree that the two concepts partly overlap and that sympathy is an affective response that frequently stems from empathy and consists of feelings of concern for the distressed or needy other person, rather than feeling the same emotion as the other person, which is closer to empathy [69]. In the present study, sympathy is taken in one of its ordinary usages, especially in French-speaking countries, i.e. the affinity, association, or relationship between persons or things wherein whatever affects one similarly affects the other. Our definition is a combination of empathy and sympathy, and reflects at a common sense level how we may in everyday life automatically interrelate with other people. Such a definition is also close to what Hodges and Wegner

\footnotetext{
${ }^{1}$ Levy suggests that "the word" empathy "be deleted from the technical language of psychology and replaced by a less ambiguous word or words" [57].
} 
[48] define as automatic empathy as opposed to controlled empathy and to what Nichols characterizes as a "concern mechanism" [66], which is considered to depend on a minimal capacity for mind-reading and also on the affective system.

It has been shown that very young infants express what Trevarthen [83] terms intersubjective sympathy, i.e. they are predisposed to be sensitive and responsive to the subjective states of other persons. This can be demonstrated through several means, including the spontaneous face-to-face interaction between infants and their mothers and through more specialized "still-face procedures" (i.e. when mothers adopt a neutral face and stop responding to the infant), which leads to withdrawal by the infant. Developmental studies have also shown that the newborns can imitate various body movements performed by adults, for example mouth opening, tongue protrusion, lip pursing, finger movements, and also emotional expressions [64,71]. It has been hypothesized that infant imitation depends on the recognition that the other is a psychological agent like oneself [7], what Meltzoff and Moore have termed a "like-me mechanism" [62]. Other research suggests that early on infants develop a sense of themselves as agents capable of causing changes in the physical environment, as well as communicative and reciprocating social agents [73]. These findings have led Gallagher and Meltzoff [34] to propose that the understanding of the other person is primarily a form of embodied practice. The initial connection between self and other, so-called primary intersubjectivity, may be the foundation for developmentally more sophisticated accomplishments, such as the perception of dispositions and intentions in other individuals $[64,73]$.

Sympathy and empathy may be viewed as other-oriented moral sentiments that may trigger altruistic desires $[6,66,80]$. This may be because an overt motivation for prosocial behavior is triggered when the self covertly (and automatically) resonates with the other, to use the metaphor of resonance that Gibson [37] and then Shepard [78] expressed. ${ }^{2}$ Such resonance is probably neurologically hard-wired, as developmental research suggests, but it is most likely a distributed neural mechanism. Moreover, this resonance phenomenon is consistent with the notion of "shared representations", which postulates that perception and action share common cognitive and neural codes $[8,12,42,50,54]$. According to this model, perception of a given behavior in another

\footnotetext{
2 The concept of resonance requires both parallel processing, a radically modern idea in Gibson's time, and a group of mechanisms with which to resonate. Later, Shepard [78] proposed that, as a result of biological evolution and individual learning, the organism is, at any given moment, tuned to resonate to the incoming patterns that correspond to the invariants that are significant for it. Interestingly, Shepard [78] proposed that the external constraints that have been most invariant throughout evolution have become most deeply internalized, and even in the complete absence of external information, the system can be excited entirely from within (while dreaming, for example). Thus, unlike Gibson, Shepard makes explicit reference to internal representation and, to our opinion, makes possible to articulate the notion of resonance with that of shared representations.
}

individual automatically activates one's own representations for the behavior [24]. Such a model is similar to the so-called simulation theory [46]. ${ }^{3}$ Evidence for this model derives from neurophysiological investigations [27,28], as well as from several functional imaging studies that have shown similar patterns of neurodynamic activity in the premotor and in the posterior parietal cortices when subjects observe actions performed by another individual and when they actually perform or mentally simulate the same actions [11-13,21,22,40,41,75]. One other neuroimaging study [10] has even demonstrated somatosensory activation in a somatotopic manner in the premotor cortex during action observation. Electrophysiological measurements have also shown that when subjects observe hand movements, there is a desynchronization over the motor cortex similar to which occurs during actual movements $[14,44]$. Further evidence for the neural substrate of shared representations has recently been provided by neuroimaging studies of imitation in humans [11,13,21,53]. Importantly, these studies have consistently pointed out the crucial role of the parietal cortex not only when the self resonates with the other, but also in distinguishing the self from the other.

Contemporary cognitive neuroscience has also made considerable progress in understanding the anatomical organization of emotional processing $[3,56]$ and points to the role of several neural circuits such as the amygdala and the adjacent cortices, the orbitofrontal cortex, and the insula. Interestingly, it has recently been discovered that patients with right hemisphere lesions in the somatosensory-related cortex are impaired in the recognition of emotion [4]. This finding has led Adolphs and colleagues to suggest that to recognize another's display of emotion, individuals covertly reconstruct an on-line somatosensory representation. This suggestion parallels the shared representations account of our ability to make sense of the behavior of others $[8,42,54]$, which to some extent, overlaps simulation theory of the philosophers of mind, which says that we use our cognitive capacities to simulate and pretend to be in the situation of others $[38,39,45]$.

We suggest that sympathy, which involves the affective experience of another person's actual or inferred emotion, can be tackled using the "shared representations" model. We are aware that sympathy is a complex construct that involves a variety of different cognitive and emotional processes. In the present experiment, we tested whether, as the shared representations model postulates, brain regions involved in feeling

\footnotetext{
${ }^{3}$ The simulation theory developed by Hesslow [46] is based on three assumptions about brain function: (1) behavior can be simulated by activating motor structures, as during an overt action but suppressing its execution; (2) perception can be simulated by internal activation of sensory cortex, as during normal perception of external stimuli; (3) both overt and covert actions can elicit perceptual simulation of their normal consequences. In the domain of emotion processing, Adolphs considers the simulation hypothesis as a plausible mechanism for recognizing emotion from faces [5].
} 
sympathy with another individual rely on the involvement of both the neural circuit for affective processing (the amygdala and the adjacent cortices, the orbitofrontal cortex, and the insula) and the neural circuit underlying shared neural representations for observed and executed actions (inferior parietal lobule and premotor cortex). Knowing that the feelings of empathy and sympathy most commonly arise when people directly perceive individuals in trouble or have a personal connection with them, we presented the subjects with dynamic stimuli that were created to elicit such a feeling. For that purpose we asked semi-professional stage actors to tell short stories whose narrative contents were either sad or neutral, as if they had personally experienced them. We further hypothesized that the feeling of sympathy would be disrupted or at least reduced if there was a mismatch between the narrative content of the stories and the emotional expression displayed by the actors (especially when a sad story is expressed with an happy expression). This situation may be considered, from the perspective of the viewers, as a sort of unexpected social situation, an inappropriate behavior that is less likely to motivate shared feelings with story protagonists. We, therefore, predicted that neural responses in regions known to be involved in dealing with social conflict and negative affect, namely in the ventromedial prefrontal cortex and the superior frontal gyrus [80] would be enhanced during the mismatch condition. In order to meet these experimental criteria, we asked the actors to tell the stories with either neutral, happy, or sad motor expressions of emotion. Their performances were video-taped and then edited to meet the constraints of a PET-activation study. Subjects were scanned while viewing these stimuli and after each session they were asked to evaluate the mood of the person they had seen and how likable (in the broad sense of feeling sympathy) they found that person. We hypothesized that the mismatch conditions would elicit feeling of dislike because they violate social norms. This effect should be particularly strong when story protagonists tell sad stories with happy motor expression of emotion (MEE). Finally, feeling sympathy for someone is not the inability to keep track of who is who even though the shared representations network is involved. It also requires distinguishing the perspectives of the self from those of the other. We, thus, expected to detect right parietal activation since this region plays a pivotal role in mediating this process $[21,29,75]$.

\section{Material and methods}

\subsection{Conditions}

The experimental conditions were based on a factorial plan (Table 1) in which the factors were the narrative content of the story (NCS; two values, neutral, N; and sad, S) and the motor emotional expression of the story-teller (three values, happy, H; neutral, N; and sad, S).
Table 1

Six experimental conditions

\begin{tabular}{llll}
\hline NCS & MEE & & \\
\cline { 2 - 4 } & Happy & Neutral & Sad \\
\hline Neutral & NH & NN & NS \\
Sad & SH & SN & SS
\end{tabular}

The factors were the narrative content of the story (NCS) and the motor expression of emotion (MEE) of the story-teller.

\subsubsection{Stimuli preparation}

In all the conditions, the stimulus consisted of a video-clip depicting one person telling one story in the first-person tense. A major concern when preparing the stimuli was that they should be well-balanced in terms of length (between 200 and 250 words), lexicon, and events depicted in the story, as well as approximately equally emotional throughout, while remaining as realistic as possible.

\subsubsection{Stories-Factor "narrative content of the story" (NCS)}

Twelve neutral and 12 sad stories were written. Neutral stories were based on everyday life actions (e.g. shopping, cooking). Sad stories were based on sad events that could have happened to anyone or had been described in newspapers (e.g. illness of a close relative, drowning accident). All stories were adapted to the story-teller's gender and age so that it appeared that the events described could have happened to them.

\subsubsection{Actors-Factor "motor expression of emotion" (MEE)}

Seven semi-professional male stage actors were recruited to tell the different stories and were paid for their participation. Actors' ages were matched to those of the subjects (20-25 years old). A set of six stories (three neutral, three sad) was assigned to every actor, and the actors were instructed to tell each story with three different expressions (neutral, happy, or sad).

\subsubsection{Video recording and editing}

Color videos were recorded using a Sony digital camera in a quiet environment. All actors were similarly lighted with artificial lights. The actors were seated in front of a black background, and the videos were shot in close-ups that included only the head and chest. Actors were required not to move their hands into the video frame. Video-clips were then edited on a Mac G3 with iMovie ${ }^{\mathrm{TM}}$ to similar lengths (between 60 and $80 \mathrm{~s}$ ) and to remove actors' hesitations.

\subsubsection{Validation of the stimuli}

All video-clips were shown to a group of 10 individuals (different from the subjects who were scanned but in the same age range) to ensure that the videos were experimentally valid. These persons were asked to watch each video and rate whether the story was credible and whether the 
facial expressions of emotion were congruent with the narrative content of the story. One set of stimuli from the same actor was then excluded because he was not considered convincing.

\subsubsection{Subjects}

Twelve right-handed healthy male volunteers $(22.35 \pm$ 1.25 years) participated. They gave written informed consent and were paid for their participation. No subject had a history of neurological, major medical, or psychiatric disorder. Subjects completed a French translation of Merhabian's balanced emotional empathy scale (BEES) [62]. The study was approved by the local Ethics Committee (CCPPRB, Centre Léon Bérard, Lyon) and conducted in accordance with the Declaration of Helsinki.

\subsection{Data recording}

\subsubsection{PET scanning}

A Siemens CTI HR+ $(63$ slices, $15.2 \mathrm{~cm}$ axial field of view) PET tomograph with collimating septa retracted operating in 3D mode was used. Sixty-three contiguous transaxial images with a slice thickness of $2.42 \mathrm{~mm}$ were acquired simultaneously. Correction for attenuation was made using a transmission scan collected at the beginning of each subject's session.

A venous catheter to administer the tracer was inserted in an antecubital fossa vein in the left forearm. After a 9-mCi bolus injection of $\mathrm{H}_{2}{ }^{15} \mathrm{O}$, scanning was started when the brain radioactive count rate reached a threshold value and continued for $60 \mathrm{~s}$. Integrated radioactivity accumulated in $60 \mathrm{~s}$ of scanning was used as an index of rCBF. Twelve scans were acquired per subject, and the interval between successive scans was 8 min.

\subsubsection{Physiological measures}

Skin conductance (SCR), blood volume pulse (BVP) and respiratory rates were collected with ProComp $+{ }^{\mathrm{TM}}$ and digitally sampled at $32 \mathrm{~Hz}$ on a computer using BioGraph 2.1 software (Thought Technology Ltd., Montreal, Canada). Skin conductance was recorded using two $1 \mathrm{~cm}^{2} \mathrm{Ag}-\mathrm{AgCl}$ electrodes attached to the last phalange of the thumb and medial phalange of the index finger of the non-dominant hand. BVP was recorded with a photoplethysmograph positioned on the last phalange of the second finger. Respiration was recorded with a chest strap disposed under the arms.

\subsubsection{Behavioral measures}

At the end of each video-clip, subjects were asked to answer two separate questions using non-graduated analogical scales. The first question was "How did you find this person's mood?" and the second, "How likable did you find this person?" The questions were presented through the same visual display as the video-clips, with the PC used to record physiological data. Participants were instructed to use a cord- less computer mouse to move a slider on a continuous scale with the adjectives "sad" or "happy" at extremes of the scale for the first question, and with "not at all" or "very much" for the second one. The scales were then divided into equal intervals by a program that scored the ratings from -100 to +100 .

\subsubsection{Repartition of conditions}

The six conditions (NH, NN, NS, SH, SN, SS, see Table 1) were duplicated once so that 12 scans were recorded per individual. The order of conditions was partially randomized so that the condition yielding a strong reaction, $\mathrm{SH}$, was presented during the second half of the experiment. Other conditions were randomized for each subject with the constraints that each actor was seen twice, once for each type of story but with different tones, and that two successive scans depicted different conditions and different actors. Each subject was presented with a unique sequence of the conditions when it came to assignment of actors and stories to the six experimental conditions and to condition order.

\subsubsection{Sequence of events}

On their arrival, subjects were placed in the PET scanner, and a transparent screen was positioned at the back of the scanner. A mirror was placed in front of the subjects so they could see the video-clips projected on the back screen. The resultant distance from the eyes to the screen was approximately $50 \mathrm{~cm}$ (corresponding field of view: $42^{\circ}$ in the horizontal dimension and $32^{\circ}$ in the vertical one). Physiological sensors were placed on the subjects, and the mouse pad was positioned at their chest level, and two audio speakers in front of the scanner.

Before the first condition, subjects were told that they were going to be presented with individuals who would tell them stories about things that happened to them, and that they would see each of these individuals twice in the course of the PET experiment. Subjects were also informed that the content of the stories, as well as the people telling them, might be more or less sad, neutral or happy. They were then shown how to use the analogical scales to answer the two questions.

Projection of the video-clips, using a VCR connected to a projector at the back of the PET scanner, and recording of the physiological data, using a portable PC, started at the same time. Because of the variability of the duration of the different stories, PET scanning started at a different time for the different conditions so that the $60 \mathrm{~s}$ scanning window did always correspond to the last $60 \mathrm{~s}$ of the video-clip. This did not bias the experiment because the last minute of each video-clip was systematically more emotive than what occurred before this minute. After the end of the video-clip, subjects were presented with the two questions on the same screen and answered them using the mouse. Therefore, the experimenter did not interfere between the end of the projection of the video-clip and the recording of the answer to the questions. 


\subsection{Statistical analysis}

\subsubsection{Behavioral performances}

Statistical analysis of subjects' ratings of the two questions $([-100,+100])$ was performed with SPSS $^{\mathrm{TM}}$ using an ANOVA with two within-subject factors corresponding to the experimental factors, "narrative content of the story" and "motor expression of emotion". Factors and interactions for which a significant effect $(P<0.05)$ was found with the ANOVA were further explored. Pairwise comparisons between the means of the subjects' responses for the factors-when a factor main effect is present in the ANOVA - or between the means of the subjects' responses for the conditions-when the effect is associated with an interaction between the two factors-were calculated using Wilcoxon rank test for significant differences in subjects' responses to different values of a factor or to different conditions.

\subsubsection{Physiological data analysis}

Data reduction of physiological measures was performed with Biograph 2.1 and Matlab 6.1, and statistical analysis with SPSS. We will focus on the SCR analysis, for it was the only physiological measure yielding statistically significant modification in relation to the experimental paradigm. SCR was calculated as the area between the curve of the skin conductance and a regression line during the last $50 \mathrm{~s}$ of the recording. This allows correction for drift of skin conductance [17]. Results were then normalized through division by the subject's mean value. Statistical analysis of the reduced measures was conducted as for the behavioral data (see Section 2.3.1).

\subsubsection{Functional neuroimaging analysis}

Functional image fixed effects analyses were performed with statistical parametric mapping software (SPM99, Welcome Department of Cognitive Neurology, UK [31]) implemented in Matlab 6 (Math Works, Natick, MA, USA). The scans of each subject were automatically realigned and then stereotactically normalized into the space of the Montreal Neurological Institute (MNI) template used in SPM99 (i.e. an average of 152 individual MRI scans representative of the population). Images were then smoothed with a Gaussian kernel of 10-mm full-width at half-maximum. The voxel dimensions of each reconstructed scan were $2 \mathrm{~mm} \times 2 \mathrm{~mm} \times 4 \mathrm{~mm}$ in the $x, y$, and $z$ dimensions, respectively.

The design for statistical analysis in SPM was defined as "multisubjects and multiconditions" with 115 d.f. Global activity for each scan was corrected by grand mean scaling. The conditions (covariate of interest) and subject (confound, fixed effect) effects were estimated voxel-wise according to the general linear model. The main effect of a given value for a factor was calculated by contrasting all conditions in which the factor has this given value to all conditions in which the factor has the neutral value. Interactions were calculated as follow:

- the interaction between the NCS and the value "happy" of the MEE:

$(\mathrm{SH}-\mathrm{NH})-(\mathrm{SN}-\mathrm{NN})$ masked inclusively with $(\mathrm{SH}-\mathrm{NH})$;

- between the NCS and the value "sad" of the MEE:

(SS-NS)-(SN-NN) masked inclusively with (SS-NS).

The inclusive masking was used to confirm the direction of the contrast. The different contrasts between conditions were used to create SPM $\{t\}$ maps, which were transformed into SPM $\{Z\}$ maps. The SPM $\{Z\}$ maps were thresholded at $P<0.0005$ for main effect analysis and at $P<0.001$ for interaction analysis, and the cluster extent thresholded at 15 voxels minimum. Condition-specific parameter estimates reflect the adjusted $\mathrm{rCBF}$ relative to the fitted mean and are expressed as a percentage of whole brain mean blood flow in a voxel of an activated cluster. Anatomical identification was performed with reference to the atlas of Duvernoy [26].

\section{Q1: How did you find the person mood?}

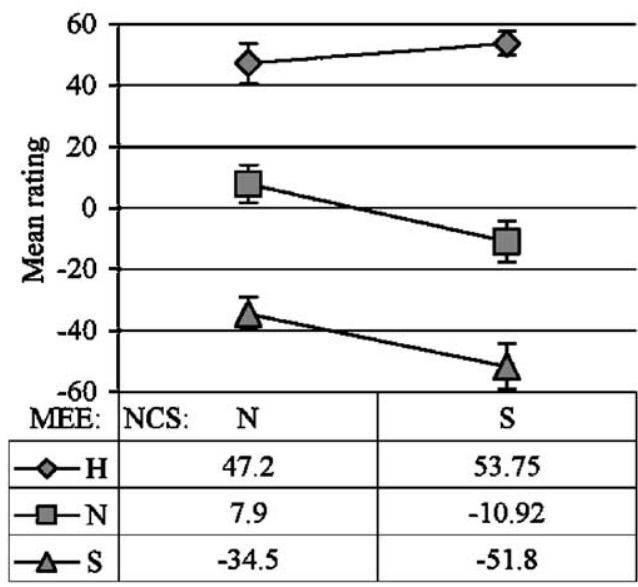

Q2: How likable did you find the person?

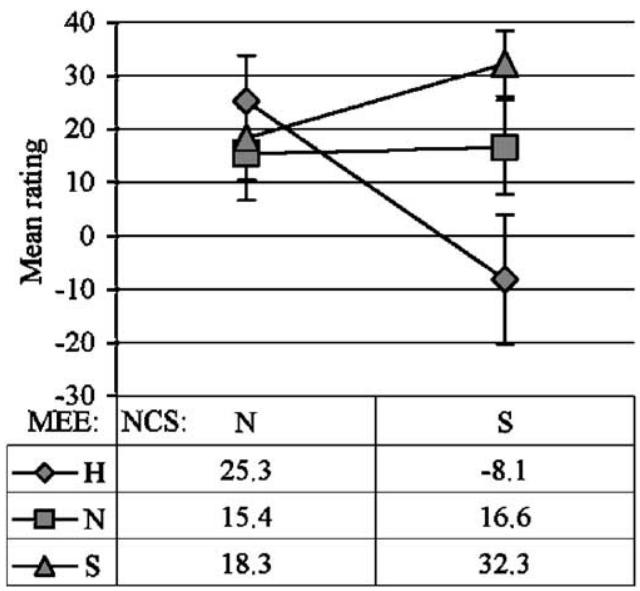

Fig. 1. Behavioral results. Graphics illustrate subjects' ratings and standard deviations (mean values are also given in tables later) corresponding to the two questions asked at the end of each video-clip in the six experimental conditions by means of analogical scales (from -100 to +100 ). 
Table 2

Main effect of sad narrative content of the story

\begin{tabular}{|c|c|c|c|c|c|}
\hline \multirow[t]{2}{*}{ Brain region } & \multicolumn{3}{|c|}{ Coordinates } & \multirow[t]{2}{*}{$Z$-score } & \multirow[t]{2}{*}{ Voxel size } \\
\hline & $x$ & $y$ & $z$ & & \\
\hline Right dorsal premotor cortex & 22 & 2 & 68 & 5.31 & 132 \\
\hline Right pre-SMA & 6 & 18 & 64 & 5.37 & 260 \\
\hline Left central sulcus & -42 & -20 & 54 & 3.81 & 17 \\
\hline Right dorsomedial prefrontal cortex & 0 & 36 & 44 & 3.63 & 22 \\
\hline Right inferior parietal lobule & 60 & -46 & 28 & 4.48 & 160 \\
\hline Right superior frontal gyrus & 22 & 50 & 30 & 4.67 & 216 \\
\hline Left superior frontal gyrus & -20 & 58 & 22 & 5.13 & 99 \\
\hline Right inferior frontal gyrus & 58 & 20 & -2 & 4.11 & 176 \\
\hline Left inferior frontal gyrus & -54 & 28 & -4 & 4.34 & 43 \\
\hline Left temporal pole & -40 & 4 & -18 & 3.76 & 46 \\
\hline Right temporal pole & 46 & 4 & -44 & 5.33 & 353 \\
\hline Left amygdala & -34 & 6 & -26 & 4.58 & 154 \\
\hline Right amygdala & 36 & 10 & -30 & 3.54 & 20 \\
\hline
\end{tabular}

Table shows regions of increased rCBF associated with the main effect for the sad NCS compared to neutral NCS (voxel extent threshold 15, $P<0.0005)$.

\section{Results}

\subsection{Subjective ratings}

The corrected BEES $z$-scores indicated that the subjects we studied were representative of the normal population on this measure of empathy in terms of range and variance [63].

Subjects' ratings of the two questions asked at the end of each scanning session are given in Fig. 1. The first question concerned the mood of the narrator. At the statistical threshold of $P<0.05$, the ANOVA indicated no effect of the NCS $(F(1,22)=3.0, P=0.11)$ but a strong effect $(F(2,22)=107.6, P<0.001)$ of the MEE on the results of the first question. As expected from the experimental design, results indicated that the highest scores were given for the happy expression (Mean $(\mathrm{M})=50.48$, standard deviation (S.D.) = 3.83), lowest for the sad expression $(\mathrm{M}=-43.12$, S.D. $=4.72)$, and close to 0 for the neutral expression $(M=-1.50$, S.D. $=4.68)$. The differences between these scores were statistically significant as assessed by Wilcoxon rank test ( $P<0.05$ for each pair).

The second question concerned how likable subjects found the person. No significant effect was found for the NCS $(F(1,22)=1.4, P=0.26)$ and for the MEE $(F(2,22)=1.2, P=0.31)$. A significant effect was found for the interaction between the NCS and the MEE $(F(2,22)=7.1, P=0.004)$. Pairwise comparisons between pairs of conditions using the Wilcoxon rank test showed that two conditions gave significantly $(P<0.05)$ different results when compared to the other ones. Results for condition SS were significantly higher, and for $\mathrm{SH}$ lower, than for the other conditions.

Debriefing of the subjects after the scanning session showed that the majority of the subjects $(9 / 12)$ thought that some stories could hardly have actually happened to the story-tellers. Nevertheless, this did not interfere with their performance of the task, and all reported that they were concerned by the stories and the communicators, and that they had no difficulties to answer the two questions.

\subsection{Physiological measures}

The skin conductance was the only physiological measure yielding statistically significant effect in relation to the experimental paradigm. The ANOVA calculated on the normalized SCR indicated no effect of either the NCS or the

Table 3

Main effects of motor expression of emotion

\begin{tabular}{|c|c|c|c|c|c|c|c|c|c|c|}
\hline \multirow[t]{2}{*}{ Brain region } & \multicolumn{5}{|c|}{ Sad vs. neutral } & \multicolumn{5}{|c|}{ Happy vs. neutral } \\
\hline & \multicolumn{3}{|c|}{ Coordinates } & \multirow{2}{*}{$\frac{Z \text {-score }}{3.43}$} & \multirow{2}{*}{$\begin{array}{l}\text { Voxel } \\
17\end{array}$} & \multicolumn{3}{|c|}{ Coordinates } & \multirow{2}{*}{$\begin{array}{l}Z \text {-score } \\
4.45\end{array}$} & \multirow{2}{*}{$\begin{array}{r}\text { Voxel } \\
104\end{array}$} \\
\hline Left inferior frontal gyrus & -44 & 16 & 8 & & & -50 & 18 & 8 & & \\
\hline Left dorsal premotor cortex & -36 & 10 & 60 & 3.57 & 16 & & & & & \\
\hline Left lateral orbital gyrus & -44 & 44 & -8 & 3.60 & 24 & & & & & \\
\hline Left temporal pole & -32 & 4 & -42 & 3.99 & 66 & & & & & \\
\hline Left superior temporal gyrus & & & & & & -56 & -26 & 6 & 4.15 & 58 \\
\hline Occipital cortex & & & & & & 2 & -94 & 4 & 6.30 & 1858 \\
\hline Left transverse orbital gyrus & & & & & & -32 & 32 & 10 & 3.82 & 25 \\
\hline
\end{tabular}

Table shows regions of increased $\mathrm{rCBF}$ associated with the main effects for the sad (on the left) and happy (on the right) MEE compared to neutral (voxel extent threshold $15, P<0.0005$ ). 
MEE (respectively, $F(1,22)=0, P=0.84, F(2,22)=2.1$, $P=0.144)$ but a significant effect for the interaction between the NCS and the $\operatorname{MEE}(F(2,22)=5.3, P=0.013)$. Experimental conditions, defined by both the NCS and the MEE, have an influence on subjects' skin conductance response.

Normalized SCR indicated stronger effect of condition SH $(M=1.3, \mathrm{SD}=0.1)$ than the other conditions, and the Wilcoxon rank test indicated that it was superior to the means for conditions NS, NH and SN $(P<0.05$ for each pair).

\subsection{Functional brain imaging results}

The brain regions associated with the main effects of the sad NCS versus neutral NCS are listed in Table 2. Most of the $\mathrm{rCBF}$ increases were bilateral (anterior superior frontal gyrus, inferior frontal gyrus, temporal pole, amygdala). In addition, rCBF increases were found in the left central sulcus and in the right dorsal premotor cortex, dorsomedial prefrontal cortex, pre-SMA, and inferior parietal lobule.

The main effect of the two values of the factor MEE (sad and happy) are listed in Table 3. The left inferior frontal gyrus was common to both expression of emotion. The left dorsal premotor cortex, lateral orbital gyrus and temporal pole were specific to the sad MEE, whereas, the occipital lobe, the orbitofrontal transverse sulcus, and the superior temporal gyrus were specific to the happy MEE.

Notably each main effect yielded a specific cluster of increased activity in the inferior frontal gyrus that were further investigated using parameter estimates (Fig. 2). In addition, their precise location was assessed using probability maps [82] to differentiate between clusters belonging to the pars opercularis and adjacent regions, in particular pars orbitalis.

Interactions between two factors indicate the effect of one factor in the context of a specific value from the second factor. The interaction between the sad MEE and the NSC, which describes the specific effect associated with condition SS, yielded rCBF increase in the left precuneus, the

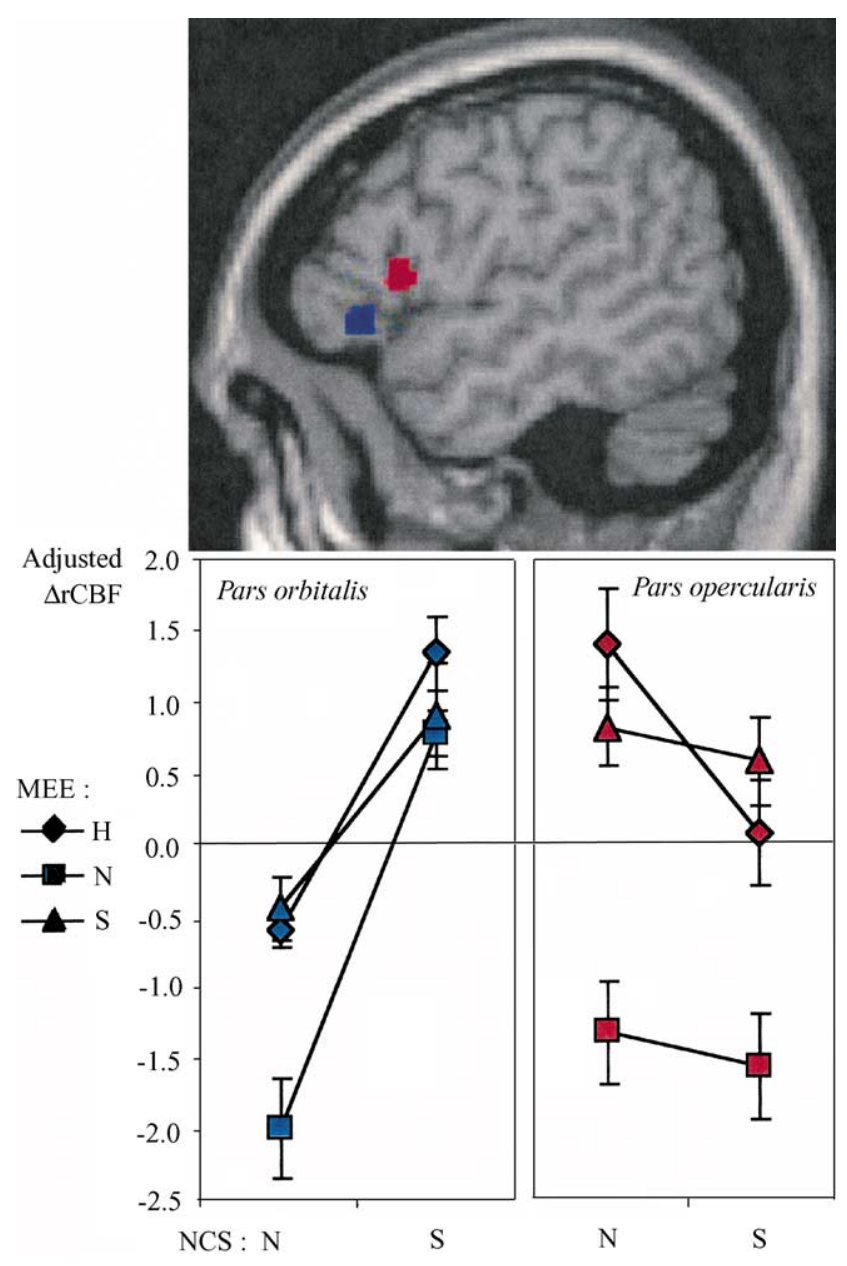

Fig. 2. Parameter estimate analysis of the two activated clusters in the inferior frontal gyrus. Graphs give the parameter estimates (i.e. adjusted $\triangle \mathrm{rCBF} \pm$ S.D.) for the six activation conditions in these two clusters superimposed to a standard MRI sagittal slice at $x=-50$ shown at the top. In blue, the pars orbitalis cluster detected in the main effect of sad narrative content of the stories and in red, the pars opercularis cluster found in the main effects of sad and happy motor expression of emotions; $\mathrm{H}$, happy; N, neutral; S, sad.

Table 4

Interaction between MEE and NCS

\begin{tabular}{|c|c|c|c|c|c|}
\hline \multirow[t]{2}{*}{ Brain region } & \multicolumn{3}{|c|}{ Coordinates } & \multirow[t]{2}{*}{$Z$-score } & \multirow[t]{2}{*}{ Voxel size } \\
\hline & $x$ & $y$ & $z$ & & \\
\hline \multicolumn{6}{|l|}{ Interaction sad MEE $\times$ happy NCS } \\
\hline Left intraparietal sulcus & -50 & -40 & 58 & 3.94 & 18 \\
\hline Right superior frontal sulcus & 24 & 42 & 36 & 3.71 & 18 \\
\hline Right inferior frontal gyrus & 38 & 6 & 28 & 4.01 & 26 \\
\hline Right superior temporal gyrus & 54 & -32 & 12 & 3.81 & 18 \\
\hline Left ventromedial prefrontal cortex & -2 & 34 & -6 & 3.59 & 27 \\
\hline \multicolumn{6}{|l|}{ Interaction sad MEE $\times$ sad NCS } \\
\hline Left precuneus & -1 & -76 & 58 & 4.07 & 19 \\
\hline Left occipital cortex & -38 & -84 & 28 & 4.23 & 82 \\
\hline Right mediodorsal thalamic nucleus & 2 & -10 & 2 & 3.67 & 15 \\
\hline
\end{tabular}

Regions in which significant rCBF increases resulted from the interaction SS (top) and from the interaction SH (bottom). Voxel extent threshold 15, $P<0.001$. 


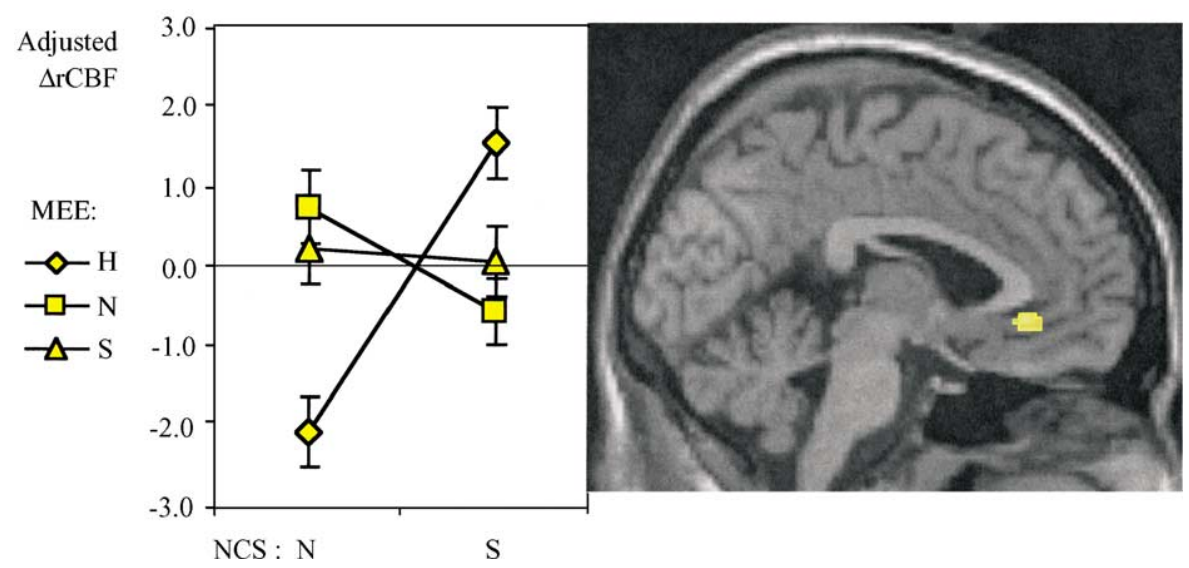

Fig. 3. Parameter estimate analysis of the cluster in the ventromedial prefrontal cortex. Graph gives the parameter estimates (i.e. adjusted $\Delta \mathrm{rCBF} \pm$ S.D.) for the six activation conditions in this cluster superimposed to a standard MRI sagittal slice at $x=-2$ shown on the right, found in the interaction describing mismatch HS condition (see Table 4); N, neutral; S, sad; H, happy.

left middle occipital gyrus, and right mediodorsal thalamic nucleus (Table 4). The interaction between the happy MEE and the NSC, describing the effect of SH, yielded rCBF increases mainly in the frontal lobe (dorsolateral, ventrolateral and ventromedial prefrontal cortex) in the anterior intraparietal sulcus and the right superior temporal gyrus. A cluster of activity in the ventromedial prefrontal cortex was further investigated using parameter estimates (Fig. 3).

\section{Discussion}

\subsection{Subjective ratings}

As expected, subjects correctly rated the motor expression of emotion (MEE) displayed by the actors (as shown in Fig. 1) and reported feeling less sympathy for the communicators in the condition of mismatch between MEE and NCS, i.e. condition SH. In addition, subjective ratings of feeling sympathy were stronger for the conditions SS.

\subsection{Functional imaging results}

The factorial design allows us to characterize brain activation due to the two main effects: the NCS, regardless of the motor expression of emotions; and the MEE, regardless of the narrative content of the stories. Furthermore, this design enables us to investigate the effect of interactions between the two factors, which indicate the effect of sad or happy MEE in the context of a sad NCS.

\subsubsection{Main effect of the narrative content of the stories}

Listening to sad stories compared to listening to neutral stories, regardless of the emotion displayed by the story-tellers, resulted in activation in neural structures known to be involved in emotional processing. Bilateral
rCBF increases in the amygdala and its adjacent cortices in the temporal poles are consistent with their role in the recognition of emotions $[1,2,85]$.

As predicted, cortical regions involved in the shared motor representations network $[8,42]$, namely the dorsal premotor cortex, pre-SMA, central sulcus, and the right inferior parietal lobule, were associated with the main effect of listening to sad stories. This was the experimental condition that was hypothesized to afford most concern towards the others and thus a strong feeling of liking. Since subjects performed no action during the conditions but merely watched video-clips, we suggest that this network is recruited to simulate, at a covert level, the affective experiences of the others (i.e. the story protagonists). More specifically, several recent studies performed by our group have demonstrated the important role played by the right inferior parietal cortex when the self takes the perspective of others $[11,21,22,29,75]$ even at the conceptual level [76]. It is interesting to recall that according to several theorists, empathizing not only necessitates a sharing of affects, but a minimal distinction between the self and the other is also mandatory [23,55-74]. Results of the present study, therefore, lead us to speculate that when subjects covertly simulate the narrative content of a sad story with the intention of rating their affinity for the communicator (i.e. how likable they found the story-teller), the distinction between their induced emotional states and the affective experiences evoked by the narrative content of the story also recruits the right inferior parietal lobule.

The right hemispheric lateralization of the simulation network could, at first glance, be related to the strong emotional value of the sad stories compared to the neutral stories, since this hemisphere is acknowledged to play a critical role in the processing of emotional behaviors [33]. However, an alternative account may be proposed. The right hemisphere is also important in Theory of Mind, the ability to attribute to oneself and others thoughts, intentions, and feelings. It has been shown that patients with acquired right hemisphere 
damage exhibit social and communicative impairments, including in their attribution of intentions to others [43]. It seems plausible that understanding the content of the stories, which rests upon an ability to track the intentions of the communicator, is a form of Theory of Mind task or at least it necessitates what Siegal and Varley [77] view as a co-option of this mechanism with language processing. The activation of the dorsomedial prefrontal cortex, which has consistently been found in neuroimaging studies that require mentalizing tasks [8,32], supports this interpretation. Notice that the two hypotheses may not be mutually incompatible, and they may support Hobson's idea that sharing emotions is the source of understanding other's feelings and intentions [47].

\subsubsection{Main effect of the motor expression of emotion}

The motor expression of emotion, regardless of the narrative content of the story, activated the same area within the left inferior frontal gyrus, as well as different areas, for the sad and happy expressions. Each main effect was associated with a cluster in the left lateral orbitofrontal cortex, which is consistent with its role in emotion processing $[3,17,56]$.

Involvement of the dorsal premotor cortex and of the temporal pole for the sad expression shows that different but functionally similar cortical regions are recruited by the two factors (i.e. MEE and NCS) triggering emotional reaction in the experimental paradigm. This could account for a process linking simulation and emotion like the one discussed in the previous section. On the other hand, the happy expression was not associated with either simulation or emotion areas, but only with primary and associative visual cortices. This contrast involves the condition of mismatch between the MEE and the NCS (SH), an unnatural social situation, that could account for the absence of brain correlates of emotional contagion, as corroborated by the low subjective ratings of likability in this condition.

\subsubsection{The case of the left inferior frontal region}

Significant activation in two distinct areas within the left inferior frontal gyrus was detected when contrasting the emotional conditions for the two factors NCS and MEE to their respective controls (Fig. 2).

Sad NCS activated an area located in the anterior part of the inferior frontal gyrus, corresponding to the pars orbitalis (Brodmann area 47/45). This is consistent with its functional role in the processing of semantic information. A large number of neuroimaging studies have indeed found selective activation of this region in semantic processing $[18,60]$. In contrast, both sad and happy MEE activated a cluster located in a more posterior and superior portion of the inferior frontal gyrus that lies at the boundary between the pars opercularis and the pars triangularis. ${ }^{4}$ This region is known to be involved in speech production since its lesion leads to Broca's aphasia. The respective roles of these

\footnotetext{
${ }^{4}$ A probability map [82] indicates a 50-75\% likelihood that this area belongs to pars opercularis.
}

two regions have been assessed by an extensive review of brain imaging studies of the semantic, lexical and phonological components of language [67]. This analysis shows that the anterior part of the inferior frontal gyrus is related to semantics while its posterior part is related to phonology.

In our study, the increased activity in the Broca areas cannot be explained by speech production since the subjects remained silent while watching the videos. Instead, we propose this activation to be associated with the visual and auditory perception of the expression of emotion displayed by the communicator. Since the Darwin's “The expression of the emotion in man and animals" [19], evidence abounds in favor of a contagion of emotion based on the covert imitation of muscular patterns associated with specific expressions (e.g. [25,84]). Similarly, the motor theory of speech perception considers that the perception of speech is based on covert imitation of the other's articulatory patterns [58]. In addition, it has been demonstrated that action production and action observation tap common neural substrates in the premotor system in a somatotopic manner [10]. Furthermore, there is now general agreement that action understanding is based on the activation of the shared representations recruited during action observation [8,12,42,72]. Broca's area is the premotor/motor region dedicated to the orofacial musculature [36]. Thus, a parsimonious interpretation of the aforementioned arguments is that similar to the role played by the other premotor areas in shared representation, Broca's region is involved in the perception of the expression of emotion. In comparison to previous neuroimaging studies that investigated emotion processing in healthy subjects, especially studies that used still faces as stimuli (for a recent review, [5]), the use of dynamic stimuli in our study is more likely to have induced such an effect.

\subsubsection{Interaction of MEE with NCS}

The experimental design included a condition of mismatch between sad story content and a happy expression of emotion displayed by the communicators, the condition $\mathrm{SH}$. This experimental manipulation was done to disrupt the feeling of sympathy in the subjects, who were witnessing a type of unfamiliar and inappropriate social behavior. The interaction describing the specific effect of this mismatch condition (Table 4) shows increased activity in the ventromedial prefrontal cortex (Fig. 3) and superior frontal gyrus. Both regions are associated with dealing with conflicts, more social for the former [81], and sensori-motor for the latter [30].

The ventromedial prefrontal cortex is anatomically connected to the amygdala and adjacent cortices, as well as to brainstem areas controlling visceral functions [70]. Interestingly, the target condition of this interaction was associated with the highest skin conductance response, which is considered as an indirect measure of emotional arousal [16]. In normal subjects, interindividual variability in the basal activity of this region has been reported to correlate with their subjective emotional experience [87]. It is consistent and predictable that this condition yield the lowest scores in the 
subjects' rating of their feeling of sympathy (Fig. 1). The activity in the ventromedial prefrontal cortex is inversely correlated with the feeling of liking of the story protagonist and correlated with the skin conductance response of the subjects. Altogether, the finding of an association between the SCR, the subjective feeling of liking, and the specific increased activity in the ventromedial prefrontal cortex is not only concordant with its role in the regulation of social behavior and in subjective emotional experience (see recent review by Adolph [5]), but also further emphasizes the relation between cognitive and emotional processes [51].

Activated clusters in the left posterior IPS and right superior temporal gyrus are likely to be related to an enhanced attentional demand [15]. Interestingly, both regions were found in an fMRI study of attention to the facial expression of emotion [65]. These regions could thus be related to an enhanced attention to the emotion displayed in the mismatch condition.

The second interaction, describing the specific effect of matching between sad MEE and NCS, resulted in rCBF increase in regions that belong to visual association cortices are known to play a role in the recall of mental images [61]. A speculative interpretation for this network's activity is that the empathetic situation affords visual imagery activity related to the story.

\section{Conclusion}

Feeling sympathy with conspecifics is a fundamental aspect of social communication, and its neurological bases are worthy of investigation from a social-cognitive neuroscience perspective. Numerous cognitive and affective mechanisms are likely to play an essential role in generating feelings of concern for others, and our study focused only on one aspect, phenomenologically rather superficial, but fundamental, of how humans are connected to one another. Subjects simply watched other individuals telling stories and were required to express how likable these individuals were to them. We think that this process is close to what Nichols [66] has characterized as a "concern mechanism" that is at the core of our capacity for altruism.

Results demonstrate that when the subjects expressed affinity for the communicator (as behaviorally assessed by the feeling of liking), both the cognitive content of the story and the motor expression of the story-teller recruit the motor representations and emotion networks. These networks seem to be associated with mentalizing abilities, and it is postulated that this results from a top-down effect of the extraction of the intentions behind the narrative content of the story. Finally, the condition that elicited the least likability (which according to our definition corresponds to the least sympathy for the other) yielded new results showing that facing inappropriate and unfamiliar social behavior activates brain areas associated with both emotional and cognitive conflicts.

\section{Acknowledgements}

The authors wish to thank Dr. Didier Le Bars, and Franck Lavenne from the CERMEP (where the PET scans were performed) for medical and technical assistance, and Anne-Évelyne Racinoux-Vallet for her help in writing the stories. We are grateful to two reviewers for their insightful comments. This research was partially supported by the INSERM and by the University of Washington Center for Mind, Brain \& Learning through funding from the Talaris Research Institute.

\section{References}

[1] Adolphs R, Tranel D, Damasio H, Damasio AR. Impaired recognition of emotion in facial expressions following bilateral damage to the human amygdala. Nature 1994;372:669-72.

[2] Adolphs R, Tranel D, Hamann S, Young AW, Calder AJ, Phelps EA, et al. Recognition of facial emotion in nine individuals with bilateral amygdala damage. Neuropsychologia 1999;37:1111-7.

[3] Adolphs R. Social cognition and the human brain. Trends in Cognitive Sciences 1999;3:469-79.

[4] Adolphs R, Damasio H, Tranel D, Cooper G, Damasio AR. A role for somatosensory cortices in the visual recognition of emotion as revealed by three-dimensional lesion mapping. Journal of Neuroscience 2000;20:2663-90.

[5] Adolphs R. Recognizing emotion from facial expressions: psychological and neurological mechanisms. Behavioral and Cognitive Neuroscience Reviews 2002;1:21-62.

[6] Batson CD. The altruism question: toward a social-psychological answer. Hove: Lawrence Erlbaum Associates; 1991.

[7] Bermudez JL, Marcel A, Eilan N. The body and the self. Cambridge: MIT Press, 1995.

[8] Blakemore S-J, Decety J. From the perception of action to the understanding of intention. Nature Reviews Neuroscience 2001; 2:561-7.

[9] Brothers L. The neural basis of primate social communication. Motivation and Emotion 1990;14:81-91.

[10] Buccino G, Binkofski F, Fink GR, Fadiga L, Fogassi L, Gallese $\mathrm{V}$, et al. Action observation activates premotor and parietal areas in a somatotopic manner: an fMRI study. European Journal of Neuroscience 2001;13:400-4.

[11] Chaminade T, Decety J. Leader or follower? Involvement of the inferior parietal lobule in agency. NeuroReport 2002;15.

[12] Chaminade T, Meary D, Orliaguet JP, Decety J. Is perceptual anticipation a motor simulation? A PET study. NeuroReport 2001;12:3669-74.

[13] Chaminade T, Meltzoff AN, Decety J. Does the end justify the means? A PET exploration of the mechanisms involved in human imitation. Neuroimage 2002;12:318-28.

[14] Cochin S, Barthelemy C, Roux S, Martineau J. Observation and execution of movement: similarities demonstrated by quantified electroencephalography. European Journal of Neuroscience 1999;11:1839-42.

[15] Coull JT, Frith CD. Differential activation of right superior parietal cortex and intraparietal sulcus by spatial and non-spatial attention. Neuroimage 1998;8:176-87.

[16] Critchley HD, Elliott R, Mathias CJ, Dolan RJ. Neural activity relating to generation and representation of galvanic skin conductance responses: a functional manetic resonance imaging study. The Journal of Neuroscience 2000;15:3033-40.

[17] Damasio AR, Grabowski TJ, Bechara A, Damasio H, Ponto LLB, Parvizi J, et al. Subcortical and cortical brain activity during the feeling of self-generated emotions. Nature Neuroscience 2000;3:1049-56. 
[18] Dapretto M, Bookheimer SY. Form and content: dissociating syntax and semantics in sentence comprehension. Neuron 1999;24:427-32.

[19] Darwin C. The expression of the emotions in man and animals. Glasgow: Fontana Press; 1889/1998.

[20] Davis MH. Empathy a social psychological approach. Madison: Westview Press; 1994.

[21] Decety J, Chaminade T, Grèzes J, Meltzoff AN. A PET Exploration of the neural mechanisms involved in reciprocal imitation. Neuroimage 2002;15:265-72.

[22] Decety J, Grèzes J, Costes N, Perani D, Jeannerod M, Procyk E, et al. Brain activity during observation of actions: influence of action content and subject's strategy. Brain 1997;120:1763-77.

[23] Decety J. Naturaliser l'empathie [Empathy naturalized]. L'Encéphale 2002;28:9-20.

[24] Decety J, Chaminade T. The neurophysiology of imitation and intersubjectivity. In: Hurley S, editor, Perspectives on imitation: from cognitive neuroscience to social science. Cambridge, MA: MIT Press; in press.

[25] Dimberg U, Thunberg M, Elmehed K. Unconscious facial reactions to emotional facial expressions. Psychological Science 2000;11:86-9.

[26] Duvernoy HM, Cabanis EA, Vannson JL. The human brain: surface, three-dimensional sectional anatomy and MRI. Wien, New York: Springer-Verlag; 1991.

[27] Fadiga L, Fogassi L, Pavesi G, Rizzolatti G. Motor facilitation during action observation: a magnetic stimulation study. Journal of Neurophysiology 1995;73:2608-11.

[28] Fadiga L, Craighero L, Buccino G, Rizzolatti G. Speech listening specifically modulates the excitability of tongue muscles: a TMS study. European Journal of Neuroscience 2002;15:399-402.

[29] Farrer C, Fanck N, Georgieff N, Frith CD, Decety J, Jeannerod M. Modulating agency: A PET study. Neuroimage, in press.

[30] Fink GR, Marshall JC, Halligan PW, Frith CD, Driver J, Frackowiak RSJ, et al. The neural consequences of conflict between intention and the senses. Brain 1999;122:497-512.

[31] Friston KJ, Ashburner J, Frith CD, Poline J-B, Heather JD, Frackowiak RSJ. Spatial registration and normalization of images. Human Brain Mapping 1995;2:165-89.

[32] Frith U. Mind blindness and the brain in autism. Neuron 2002;6:96979

[33] Gainotti G. Neuropsychology of emotion. In: Denes G, Pizzamiglio L, editors, Handbook of clinical and experimental neuropsychology. Hove: Psychology Press; 1999, p. 613-33.

[34] Gallagher S, Meltzoff AN. The earliest sense of self and others: Merleau-Ponty and recent developmental studies. Philosophical Psychology 1996;9:211-33.

[35] Gallagher S. The practice of mind: theory, simulation or primary interaction? Journal of Consciousness Studies 2001;8:83-108.

[36] Geyer S, Matelli M, Luppino G, Zilles K. Functional neuroanatomy of the primate isocortical motor system. Anatomy and Embryology 2000;202:443-74.

[37] Gibson JJ. The senses considered as perceptual systems. Boston, MA: Houghton Mifflin, 1966.

[38] Goldman A. Interpretation psychologized. Mind and Language 1989;4:104-19.

[39] Gordon R. Folk psychology as simulation. Mind and Language 1986;1:158-71.

[40] Grafton ST, Arbib MA, Fadiga L, Rizzolatti G. Localization of grasp representations in humans by positron emission tomography: observation compared with imagination. Experimental Brain Research 1996;112:103-11.

[41] Grèzes J, Costes N, Decety J. The effects of learning and intention on the neural network involved in the perception of meaningless actions. Brain 1999;122:1875-87.

[42] Grèzes J, Decety J. Functional anatomy of execution, mental simulation, observation, and verb generation of actions: a metaanalysis. Human Brain Mapping 2001;12:1-19.

[43] Happé F, Brownell H, Winner E. Acquired mind-blindness following stroke. Cognition 1999;70:211-40.
[44] Hari R, Forss N, Avikainen S, Kirveskari E, Salenius S, Rizzolatti G. Activation of human primary motor cortex during action observation: a neuromagnetic study. Proceedings of the National Academy of Sciences USA 1998;95:15061-5.

[45] Heal J. Replication and functionalism. In: Butterfield J, editor, Language, mind and logic. Cambridge: Cambridge University Press; 1986, p. 135-150.

[46] Hesslow G. Conscious thought as simulation of behavior and perception. Trends in Cognitive Sciences 2002;6:242-7.

[47] Hobson RP. On sharing experiences. Development and Psychopathology 1989;1:197-203.

[48] Hodges SD, Wegner DM. Automatic and controlled empathy. In: Ickes W, editor, Empathic accuracy. New York: The Guilford Press; 1997, p. 311-39.

[49] Hoffman ML. Empathy and moral development. Cambridge: Cambridge University Press; 2000.

[50] Hommel B, Musseler J, Aschersleben G, Prinz W. The theory of event coding: a framework for perception and action planning. Behavioral and Brain Sciences, in press.

[51] Houdé O, Zago L, Crivello F, Moutier S, Pineau A, Mazoyer B, et al. Access to deductive logic depends on a right ventromedial prefrontal area devoted to emotion and feeling: evidence from a training paradigm. Neuroimage 2001;14:1486-92.

[52] Hume D. A treatise of human nature. Oxford: Clarendon Press; $1888 / 1990$.

[53] Iacoboni M, Woods RP, Brass M, Bekkering H, Mazziotta JC, Rizzolatti G. Cortical mechanisms of human imitation. Science 1999;286:2526-8.

[54] Jeannerod M. Mental imagery in the motor context. Neuropsychologia 1995;33:1419-32.

[55] Kohut H. The analysis of the self. New York: International University Press; 1971

[56] LeDoux JE. The emotional brain. New York: Simon and Schuster; 1996.

[57] Levy J. A note on empathy. New Ideas in Psychology 1997;15:47984.

[58] Liberman AM, Mattingley IG. The motor theory of speech perception revise. Cognition 1985;21:1-36.

[59] Losoya SH, Eisenberg N. Affective empathy. In: Hall JA, Bernieri FJ, editors, Interpersonal sensitivity. Mahwah: Lawrence Erlbaum Associates, 2001, p. 21-43.

[60] Martin A, Wiggs CL, Ungerleider LG, Haxby JV. Neural correlates of category-specific knowledge. Nature 1996;379:649-52.

[61] Mellet E, Tzourio-Mazoyer N, Bricogne S, Mazoyer B, Kosslyn SM, Denis M. Functional anatomy of high-resolution visual mental imagery. Journal of Cognitive Neuroscience 2000;12:98-109.

[62] Meltzoff AN, Moore MK. Infants' understanding of people and things: from body imitation to folk psychology. In: Bermudez JL, Marcel A, Eilan N, editors. The body and the self. Cambridge: MIT Press; 1995, p. 43-69

[63] Merhabian A. Manual for the balanced emotional empathy scale (BEES). Available from Albert Merhabian, 1130 alta Mesa Road, Monterey, CA 93940.

[64] Nadel J, Butterworth G. Imitation in Infancy. Cambridge: Cambridge University Press; 2000.

[65] Narumoto J, Okada T, Sadato N, Fukui K, Yonekura Y. Attention to emotion modulates fMRI activity in human right superior temporal sulcus. Cognitive Brain Research 2001;12:225-31.

[66] Nichols S. Mindreading and the cognitive architecture underlying altruistic motivation. Mind and Language 2001;16:425-55.

[67] Poldrack RA, Wagner AD, Prull MW, Desmond JE, Glover GH, Gabrieli JD. Functional specialization for semantic and phonological processing in the left inferior prefrontal cortex. Neuroimage 1999;10:15-35.

[68] Povinelli DJ, Giambrone S. Inferring other minds: failure of the argument by analogy. Philosophical Topics 1999;27:167-201.

[69] Preston SD, De Waal FBM. Empathy: its ultimate and proximate bases. Behavioral and Brain Science, in press. 
[70] Price JL. Prefrontal cortical networks related to visceral function and mood. Annals of the New York Academy of Science 1999;877:38396.

[71] Prinz W, Meltzoff AN. The imitative mind, development, evolution and brain bases. Cambridge: Cambridge University Press; 2002.

[72] Rizzolatti G, Fogassi L, Galesse V. Neurophysiological mechanisms underlying the understanding and imitation of action. Nature Review Neuroscience 2001;2:665-70.

[73] Rochat P, Striano T. Perceived self in infancy. Infant Behavior and Development 2000;23:513-30.

[74] Rogers CR. A theory of therapy, personality and interpersonal relationships as developed in the client-centered framework. In: Koch S, editor. Psychology: a study of a science, vol. 3. Formulations of the person in the social context. New York: McGraw-Hill; 1959, p. $184-256$.

[75] Ruby P, Decety J. Effect of subjective perspective taking during simulation of action: a PET investigation of agency. Nature Neuroscience 2001;4:546-50.

[76] Ruby P, Decety J. Assessing the knowledge of others: a PET study of conceptual perspective-taking. In: Proceedings of the Abstract at Ninth Cognitive Neuroscience Society Meeting, San Francisco. 2002, B39, p. 52.

[77] Siegal M, Varley R. Neural systems involved in theory of mind. Nature Reviews Neuroscience 2002;3:463-71.

[78] Shepard RN. Ecological constraints on internal representation: resonant kinematics of perceiving, imagining, thinking, and dreaming. Psychological Review 1984;91:417-47.
[79] Smith A. The theory of moral sentiments. New York: Norton and Company; 1759/1986.

[80] Sober E, Wilson DS. Unto others. Cambridge: Harvard University Press; 1998.

[81] Stuss DT, Benson DF. The frontal lobes. New York: Raven Press; 1986.

[82] Tomaiuolo F, MacDonald JD, Caramanos Z, Posner G, Chiavaras M, Evans AC, et al. Morphology, morphometry and probability mapping of the pars opercularis of the inferior frontal gyrus: an in vivo MRI analysis. European Journal of Neuroscience 1999;11:3033-46.

[83] Trevarthen C. Communication and cooperation in early infancy. In: Bullowa $\mathrm{M}$, editor. Before speech: the beginning of human communication. London: Cambridge University Press; 1979, p. 321-347.

[84] Wallbott HG. Recognition of emotion from facial expression via imitation? Some indirect evidence for an old theory. British Journal of Social Psychology 1991;30:207-19.

[85] Wicker B, Perrett DI, Baron-Cohen S, Decety J. Being the target of others' emotions: a PET study. Neuropsychologia 2002; 1483 .

[86] Wispé L. The distinction between sympathy and empathy: to call forth a concept a word is needed. Journal of Personality and Social Psychology 1986;50:314-21.

[87] Zald DH, Mattson DL, Pardo JV. Brain activity in ventromedial prefrontal cortex correlates with individual differences in negative affect. Proceedings of the National Academy of Sciences USA 2002;99:2450-4. 